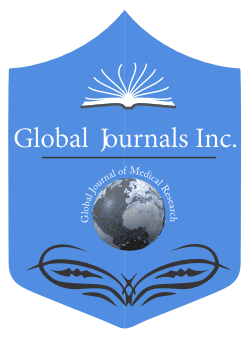

\title{
A Randomized Controlled Trial of Curcuma Longa and Boswellia Serrata Extract in Osteoarthritis
}

\author{
By Rizaldy Taslim Pinzon, Rosa De Lima Renita Sanyasi, Esdras Ardi Pramudita \\ \& Septian Dewi Periska \\ Duta Wacana Christian University School of Medicine
}

Abstract- Background: Chronic pain is the major complaint in subjects with osteoarthritis (OA). Nonsteroid anti-inflammatory drug (NSAID) is still the drug of choice in Indonesia to treat OA patients. The prolonged consumption of NSAID may lead to many adverse events (AE). Some previous studies showed the extract of Curcuma longa and Boswellia serrata is a promising potential as therapeutic interventions against $O A$.

Objective: This study aimed to evaluate the effectiveness and safety of $C B$ extract to relieve symptoms in patients with $\mathrm{OA}$.

Study Design: This was a randomized controlled trial $(\mathrm{RCT})$ in OA patients. The treatment used in this trial were CB extract (350 mg of Curcuma longa and $150 \mathrm{mg}$ Boswellia serrata) and NSAID (400 mg ibuprofen or $50 \mathrm{mg}$ diclofenac sodium). Subjects were randomized to 3 different groups (Group 1: CB extract and NSAID; group 2: CB extract; group 3: NSAID). Each medication was taken two times per day for four weeks. Paracetamol tablet $500 \mathrm{mg}$ gave to each subject as a rescue medication.

Keywords: curcuma longa, boswellia serrata, osteoarthritis, WOMAC.

GJMR-H Classification: NLMC Code: WE 348

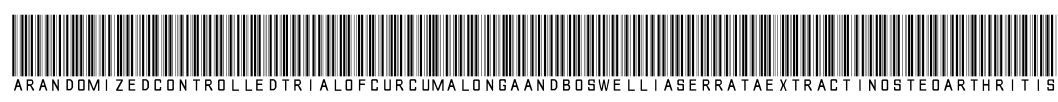

Strictly as per the compliance and regulations of:

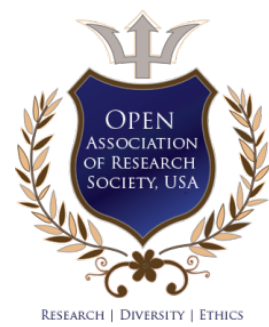

(c) 2019. Rizaldy Taslim Pinzon, Rosa De Lima Renita Sanyasi, Esdras Ardi Pramudita \& Septian Dewi Periska. This is a research/review paper, distributed under the terms of the Creative Commons Attribution-Noncommercial 3.0 Unported License http://creativecommons.org/licenses/by-nc/3.0/), permitting all non-commercial use, distribution, and reproduction in any medium, provided the original work is properly cited. 


\title{
A Randomized Controlled Trial of Curcuma Longa and Boswellia Serrata Extract in Osteoarthritis
}

\author{
Rizaldy Taslim Pinzon ${ }^{\alpha}$, Rosa De Lima Renita Sanyasi ${ }^{\circ}$, Esdras Ardi Pramudita ${ }^{\circ}$ \\ \& Septian Dewi Periska ${ }^{\omega}$
}

\begin{abstract}
Background: Chronic pain is the major complaint in subjects with osteoarthritis (OA). Non- steroid antiinflammatory drug (NSAID) is still the drug of choice in Indonesia to treat OA patients. The prolonged consumption of NSAID may lead to many adverse events (AE). Some previous studies showed the extract of Curcuma longa and Boswellia serrata is a promising potential as therapeutic interventions against $O A$.
\end{abstract}

Objective: This study aimed to evaluate the effectiveness and safety of CB extract to relieve symptoms in patients with $O A$.

Study Design: This was a randomized controlled trial (RCT) in OA patients. The treatment used in this trial were CB extract (350 mg of Curcuma longa and $150 \mathrm{mg}$ Boswellia serrata) and NSAID (400 mg ibuprofen or $50 \mathrm{mg}$ diclofenac sodium). Subjects were randomized to 3 different groups (Group 1: CB extract and NSAID; group 2: CB extract; group 3: NSAID). Each medication was taken two times per day for four weeks. Paracetamol tablet $500 \mathrm{mg}$ gave to each subject as a rescue medication. Each subject would be followed up three times: baseline (visit I), two weeks after baseline (visit II), and four weeks after baseline (visit III). The measurement was using WOMAC (Western Ontario and McMaster Universities Osteoarthritis Index).

Results: There were 105 subjects at the beginning of the study dominated by a female with mean aged 63 years and have osteoarthritis with $\mathrm{KL}$ grade II. Seven subjects were lost to follow up, and three subjects excluded from the study due to adverse event. Ninety five subjects (group 1: 36; group 2: 29, group 3: 30) remained for complete analysis. Delta $(\Delta)$ WOMAC score defined as the result of subtraction between WOMAC score at a visit I and WOMAC score at visit III. The highest mean of the WOMAC score was in group 1. However, group 1 showed the greatest reduction of WOMAC score after four weeks of treatment $(\triangle W O M A C=12.08 \pm 18.6)$. Group 3 has the least WOMAC score reduction ( $\triangle$ WOMAC $=6.9 \pm$ 16). There was no statistically different $\triangle W O M A C$ score between groups ( $p=0.367$ ). The highest consumption of rescue medication was in group 3 , whereas the least consumption was in group 2 . There was no statistical different of rescue medication consumption between groups ( $p: 0.346)$. Group 3 was the most frequently group with reported $A E$, whereas group 2 has the least reported $A E$. There were no

Author a W: Duta Wacana Christian University School of Medicine, Dr. Wahidin Sudirohusodo Street 5- 25, Yogyakarta, Indonesia, 55224.

Author $\sigma$ p: Panti Rapih Hospital, Cik Di Tiro Street 30, Yogyakarta, Indonesia, 55223. e-mail: rosasanyasi@gmail.com

Author a: Bethesda Hospital, Jendral Sudirman Street 70, Yogyakarta, Indonesia, 55223. statistically difference from the prevalence of $A E$ between groups at the visit II (p: 0.119) and the visit III (p: 0.767).

Conclusion: $\mathrm{CB}$ extract is effective for $\mathrm{OA}$ treatment and also has a better safety profile compared to NSAID.

Keywords: curcuma longa, boswellia serrata, osteoarthritis, WOMAC.

\section{INTRODUCTION}

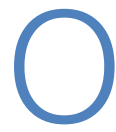
steoarthritis $(\mathrm{OA})$ is a chronic inflammatory joint disease and the most common form of arthritis (Loeser et al., 2012; Mobasheri and Mark, 2016). It is one of a common diagnosis in daily clinical practice (Lespasio et al., 2017; Neogi, 2013). It affects not only the knees but also in the hands, feet, and hips (Litwic et al., 2013). The target of OA management is to reduce pain, optimize function, and also modify the process of joint damage (Sofat and Kuttapitiya, 2014). Chronic pain is the most common complaint in subjects with OA (Cedraschi et al., 2013; Lluch et al., 2014). Therefore, patients with OA often depend on analgetic, such as non-steroid anti-inflammatory drug (NSAID). Prolonged consumption of NSAID may lead to many adverse events such as gastrointestinal tract bleeding and cardiovascular problems (Sostres et al., 2013).

Curcumin is the yellow pigment isolated from the rhizomes of Curcuma longa (CL). CL is also known as turmeric (Henrotin et al., 2013). Many type of research have been published for $\mathrm{CL}$ potency as an anti-inflammatory and analgesic properties (Henrotin et al. 2010). Curcumin has also demonstrated antiapoptotic activity in chondrocytes (Akhtar and Haqqi, 2012). Boswellia serrata (BS) is a common ingredient in Ayurvedic medicine. It also has an anti-inflammatory effect and beneficial to treat a chronic inflammatory disease (Siddiqui, 2011).

The OA process is involved in various interleukins and cytokines such as IL-1 $\beta$ and TNF $\alpha$ and proteases degrading enzymes such as MMP-3, MMP-9, and MMP-13 (Akuri et al., 2017). The anti-arthritic potential of curcumin shows its' capability to downregulate the catabolic and degradative effects in cartilage explants, or chondrocytes stimulated with IL-1 $\beta$, and TNF $\alpha$ and inhibited the production of MMP-3, MMP-9, and MMP-13 (Akhtar and Haqqi, 2012). An oral 
administration of BS extract also resulted in significantly reduced levels of inflammatory mediators (IL-1 $\beta, I L-6$, TNF- $\alpha$, IFN- $\gamma$, and PGE2) (Umar et al., 2014).

NSAID is still the drug of choice in Indonesia to treat $\mathrm{OA}$ patients (Indonesian Rheumatology Association, 2014). Many previous studies showed the extract of $\mathrm{CL}$ and $\mathrm{BS}$ is a promising potential as therapeutic interventions against $\mathrm{OA}$. The administration of $\mathrm{CL}$ extract, BS extract, or its combination is expected to reduce the amount of consumption of NSAID and reduce the adverse events due to the chronic administration of NSAID. The research of the combination of $\mathrm{CL}$ extract and BS extract (CB extract) in $\mathrm{OA}$ patients in Indonesia is very limited. The main objective of this study was to evaluate the effectiveness of $\mathrm{CB}$ extract to relieve symptoms in patients with $\mathrm{OA}$. This study also identify the safety of the administration of $\mathrm{CB}$ extract in patients with $\mathrm{OA}$.

\section{Materials and Methods}

This study was a randomized controlled trial (RCT) held at Bethesda Hospital and Panti Rapih Hospital, Yogyakarta, Indonesia. Subject enrollment at the first visit included male or female patients, age $>18$ years old, and has knee osteoarthritis with KellgrenLawrence grade II or III. Subject with a known hypersensitivity to CB extract, ibuprofen, diclofenac sodium and/or paracetamol, participation in other clinical trial in the last 1 month before this study, pregnant or has a pregnancy program, incompetent to give a consent and answer the questionnaire, or receiving other pain treatment in the last 24 hours before this study excluded in this study. The sample size calculation based on the assumption of a 95\% confidence interval and $80 \%$ power of the study. The minimum sample requirement was 25 subjects in each group. A total of 100 subjects enrolled for achieving normal distribution. Subjects divided into three groups randomly. The treatment used in this trial were $\mathrm{CB}$ extract (350 mg of Curcuma longa and $150 \mathrm{mg}$ Boswellia serrata) and NSAID (400 mg ibuprofen or $50 \mathrm{mg}$ diclofenac sodium). Group 1 received the CB extract and NSAID, group 2 received CB extract, and group 3 received NSAID. Each medication was taken two times per day for four weeks. Paracetamol tablet $500 \mathrm{mg}$ was given to each subject as a rescue medication. The remaining number of rescue medication at the third visit was calculated at the end of the study. Figure 1 shows the schematic study flowchart. Each subject signed an informed consent form. Subjects followed-up three times with interval of two weeks between each visit.

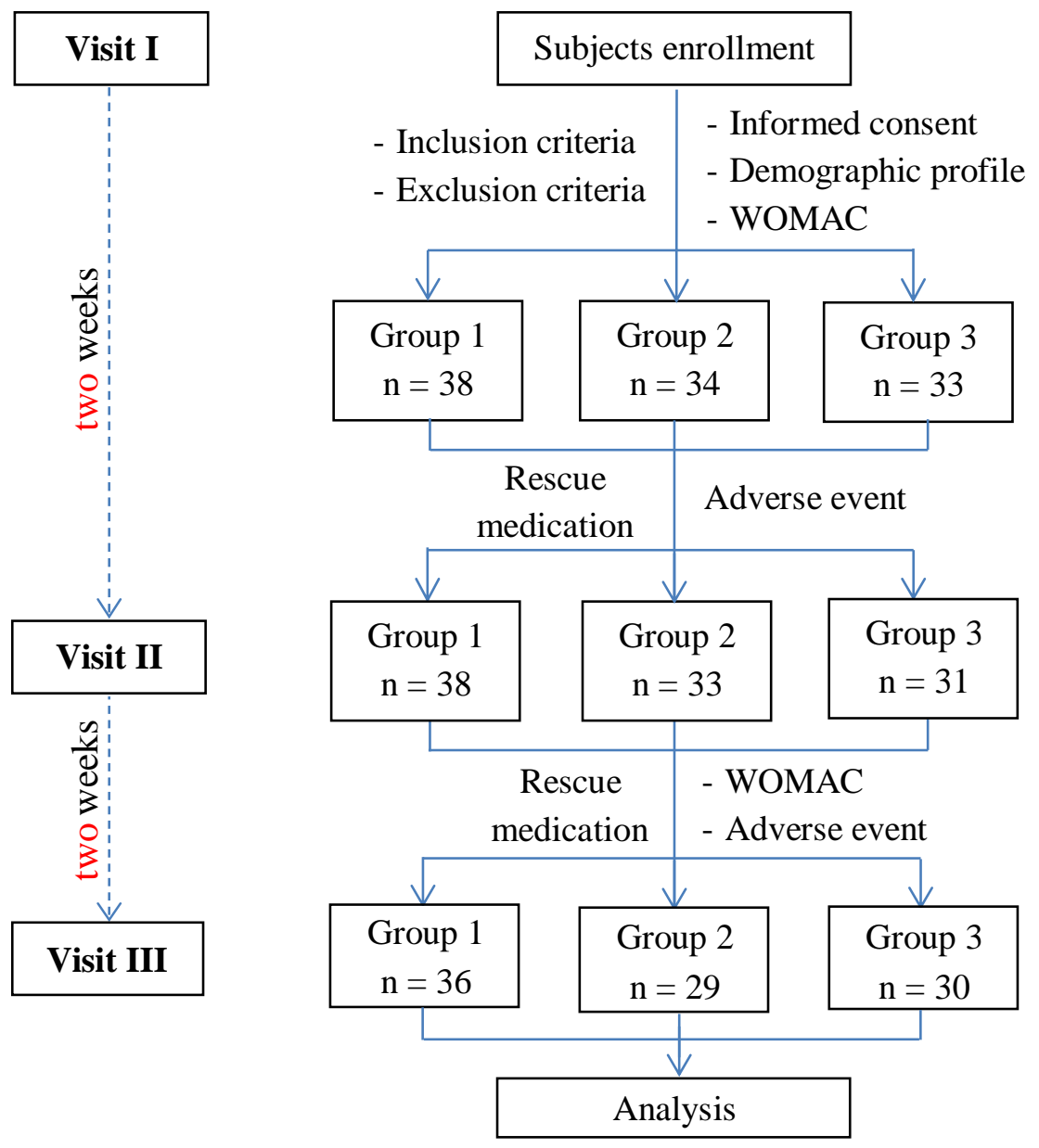

Figure 1: The flowchart of the research 
Demographic profile including sex, age, occupation, marital status, education background, comorbidity, and the degree of OA. The degree of knee $\mathrm{OA}$ was measured using the Kellgren-Lawrence $(\mathrm{KL})$ grading scale. It determined based on the result of knee X-Ray and interpreted by a radiologist. WOMAC (Western Ontario and McMaster Universities Osteoarthritis Index) commonly used as a standardized questionnaire to evaluate the condition of patients with osteoarthritis. It consists of three categories of questions, five questions for pain, two questions for stiffness, and 17 questions for physical functioning of the joints. Each question is scored on a scale of 0 to 4 $(0=$ none, $1=$ mild, $2=$ moderate, $3=$ severe, $4=$ extreme), thus score range for pain, stiffness, and physical functioning are 0-20, 0-8, and 0-68 respectively. The total score for all questions is 96 . The higher score indicates the worse OA symptom. Any adverse event $(A E)$ in this trial would be reported and monitored strictly. The assessment of AE based on the type of $A E$, the degree of $A E$, the correlation to the administration of CB extract or NSAID, and the action taken to treat the AE. All data obtained from this study is classified. This study verified by Duta Wacana Christian University School of Medicine Ethical Research Committee, Yogyakarta, Indonesia. The number of ethical clearance is $867 / \mathrm{C} .16 / \mathrm{FK} / 2018$.

The analysis of this study is the intention to treat based. The demographic profile of subjects mentioned in percentage. After the normality test with KolmogorovSmirnov test, numeric variables analyzed using a t-test or Wilcoxon signed-rank test. Based on the result of the homogeneity test, ANOVA or Kruskal Wallis test used to identify the mean differences between the three groups. The significant level was set at $p<0.05$.

\section{RESUlTS}

There were 105 subjects at the beginning of the study dominated by a female $(80 \%)$ with a mean aged 63 years. About $57.1 \%$ of the subjects have osteoarthritis with $\mathrm{KL}$ grade II. The detail of subjects' characteristics seen in Table 1. Figure 1 shows the detail of the number of subjects in each group. Seven subjects were lost to follow up and three subjects excluded from the study due to drug's side effect. Ninety-five subjects (36 subjects from group 1, 29 subjects from group 2, 30 subjects from group 3) remained for complete analysis.

Table 1: The subjects' characteristics

\begin{tabular}{|c|c|c|}
\hline \multicolumn{2}{|c|}{ Characteristics } & $\mathrm{n}(\%)$ \\
\hline Age (mean) & & $63.24 \pm 8.77$ \\
\hline \multirow{2}{*}{ Gender } & \multirow{2}{*}{ Male Female } & $21(20 \%)$ \\
& & $84(80 \%)$ \\
\hline Marital status & Married & $78(74.3 \%)$ \\
\hline & Not married & $27(25.7 \%)$ \\
\hline \multirow{2}{*}{ Occupation } & Working Not & $70(66.7 \%)$ \\
\cline { 3 - 3 } & working & $35(33.3 \%)$ \\
\hline \multirow{2}{*}{ KL Grade } & \multirow{2}{*}{ Grade II Grade III } & $60(57.1 \%)$ \\
\cline { 3 - 3 } & & $45(42.9 \%)$ \\
\cline { 3 - 3 } Comorbidity & \multirow{2}{*}{ Yes No } & $79(75.2 \%)$ \\
\cline { 3 - 3 } & & $26(24.8 \%)$ \\
\hline
\end{tabular}

DM: diabetes mellitus, CVD: cardiovascular disease, GIT: gastrointestinal

WOMAC scores tend to be higher of female subjects, single, not working, have a $\mathrm{KL}$ grade III, and without any comorbidity. An analysis in these variables proved that age, gender, marital status, occupation, the degree of $\mathrm{OA}$, and the presence of comorbidity were not correlated to the WOMAC score (Table 2).

Table 2: The WOMAC score based on subjects' characteristics

\begin{tabular}{|c|c|c|c|}
\hline \multicolumn{2}{|c|}{ Characteristics } & WOMAC Score & $\mathrm{p}$ \\
\hline Age & & & 0.870 \\
\hline Gender & $\begin{array}{l}\text { Male } \\
\text { Female }\end{array}$ & $\begin{array}{l}32.5 \pm 17 \\
37.8 \pm 19\end{array}$ & 0.247 \\
\hline Marital status & $\begin{array}{c}\text { Married } \\
\text { Not married }\end{array}$ & $\begin{array}{c}36.6 \pm 19 \\
37.2 \pm 19\end{array}$ & 0.888 \\
\hline Occupation & $\begin{array}{l}\text { Working } \\
\text { Not working }\end{array}$ & $\begin{array}{l}36.4 \pm 20 \\
37.4 \pm 16\end{array}$ & 0.793 \\
\hline KL Grade & $\begin{array}{l}\text { Grade II } \\
\text { Grade III }\end{array}$ & $\begin{array}{l}35.3 \pm 18 \\
38.7 \pm 20\end{array}$ & 0.367 \\
\hline Comorbidity & $\begin{array}{l}\text { Yes } \\
\text { No }\end{array}$ & $\begin{array}{c}36.58 \pm 19 \\
37.2 \pm 18\end{array}$ & 0.880 \\
\hline
\end{tabular}

Table 3 showed the mean of the WOMAC score at visit I and visit III from all subjects, and each group. The highest average of the WOMAC score was in group 1 and the least was in group 2. The reduction of the WOMAC score from visit I to visit III is statistically significant in all groups. 
Table 3: The result of WOMAC

\begin{tabular}{|c|c|c|c|c|c|c|c|}
\hline \multirow{2}{*}{ Group } & \multicolumn{3}{|c|}{ WOMAC I $(\mathrm{n}=105)$} & \multicolumn{3}{c|}{ WOMAC III $(\mathrm{n}=95)$} & \multirow{2}{*}{$\mathrm{p}$} \\
\cline { 2 - 7 } & $\begin{array}{c}\text { Min } \\
\text { Score }\end{array}$ & $\begin{array}{c}\text { Max } \\
\text { Score }\end{array}$ & $\begin{array}{c}\text { Mean } \\
\text { Score }\end{array}$ & $\begin{array}{c}\text { Min } \\
\text { Score }\end{array}$ & $\begin{array}{c}\text { Max } \\
\text { Score }\end{array}$ & $\begin{array}{c}\text { Mean } \\
\text { Score }\end{array}$ & \\
\hline All subjects & 3 & 73 & $39.7 \pm 19$ & 0 & 84 & $27.9 \pm 21$ & $<0.001$ \\
\hline Group 1 & 5 & 73 & $41.4 \pm 19$ & 2 & 84 & $30.3 \pm 22$ & $<0.001$ \\
\hline Group 2 & 5 & 73 & $33.9 \pm 17$ & 0 & 79 & $26.4 \pm 20$ & $<0.001$ \\
\hline Group 3 & 3 & 69 & $34.3 \pm 20$ & 1 & 65 & $26.7 \pm 21$ & 0.016 \\
\hline
\end{tabular}

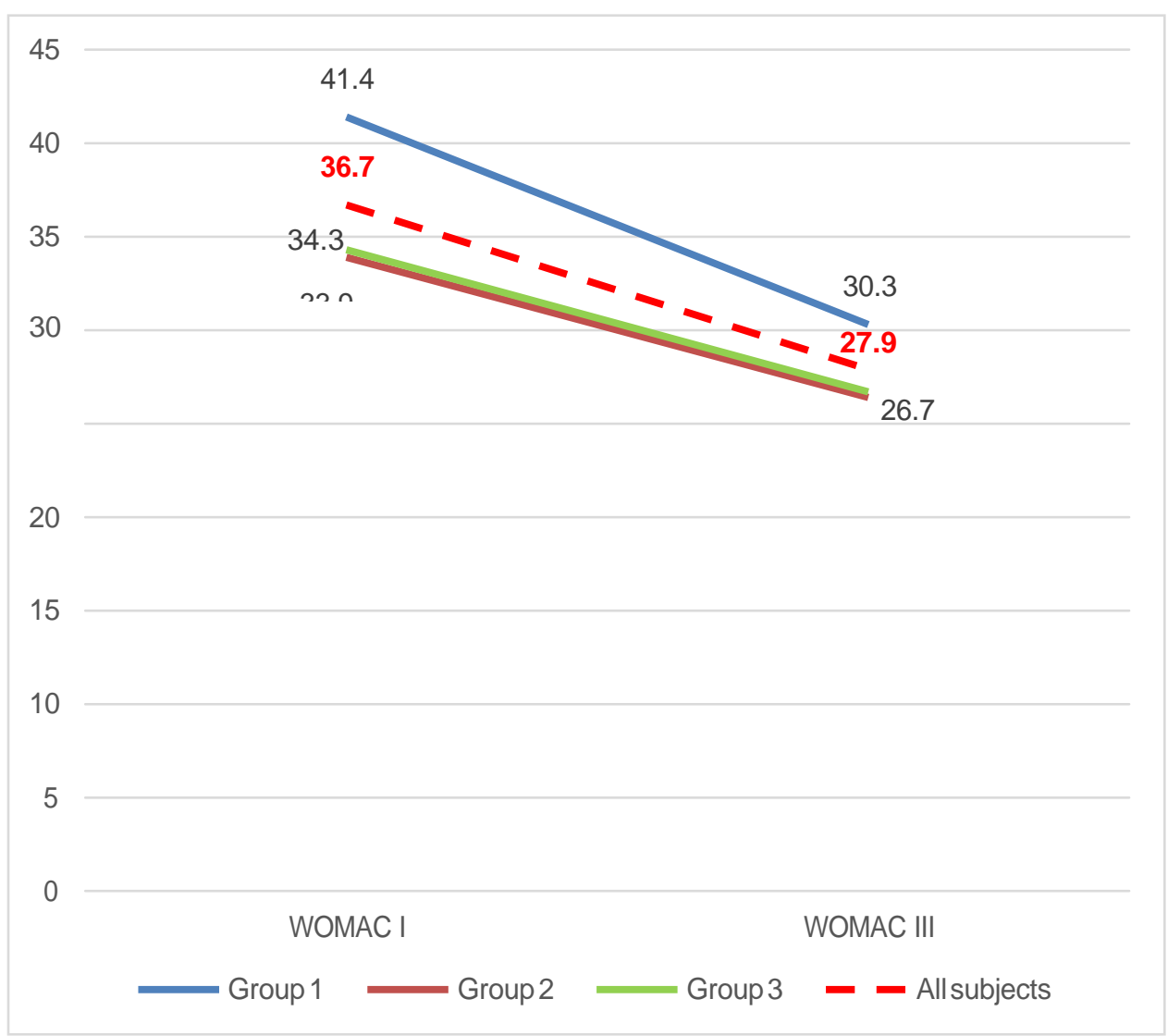

Figure 2: The comparison of WOMAC score mean

Delta $(\Delta)$ WOMAC score defined as the result of subtraction between WOMAC score at visit I and WOMAC score at visit III. The highest mean of the WOMAC score was in group 1 (Table 3 and Figure 2). However, group 1 showed the greatest reduction of WOMAC score after four weeks of treatment ( $\triangle$ WOMAC $=12.08 \pm 18.6$ ). Group 3 has the least WOMAC score reduction. There was no statistically different $\triangle W O M A C$ score between groups (Table 4).

Table 4: The mean of $\triangle$ WOMAC score

\begin{tabular}{|c|c|c|}
\hline Medication & Mean $\Delta$ WOMAC & $\mathrm{p}$ \\
\hline Group 1 (n: 36) & $12.08 \pm 19$ & 0.367 \\
\hline Group 2 (n: 29) & $7.2 \pm 14$ & \\
\hline Group 3 (n: 30) & $6.9 \pm 16$ & \\
\hline
\end{tabular}

Each subject was given 20 tablets of $500 \mathrm{mg}$ paracetamol as a rescue medication. At the end of the study, the remaining number of paracetamol calculated. The highest consumption of rescue medication was in group 3 (15 tablets of paracetamol), whereas the least consumption was in group 2 (12 tablets of paracetamol), as seen in Table 5. There was no statistical difference of rescue medication consumption between groups (p: 0.346).

Table 5: The mean remaining number of paracetamol

\begin{tabular}{|c|c|c|}
\hline Group & $\begin{array}{c}\text { The remaining number of } \\
\text { rescue medication (mean) }\end{array}$ & $p$ \\
\hline $\begin{array}{c}\text { Group 1 (n: 36) } \\
\text { Group 2 (n: 29) }\end{array}$ & $\begin{array}{c}\text { seven tablets } \\
\text { eight tablets } \\
\text { five tablets }\end{array}$ & 0.346 \\
\hline
\end{tabular}


Group 3 was the most frequent group with reported $A E$, whereas group 2 has the least reported AE. Abdominal pain was the most common type of $A E$ $(n=7)$. All of them seen in group 3. The action taken to treat $A E$ based on the symptoms, and the degree of severity. Three subjects need to discontinue the medication due to the $\mathrm{AE}$, two among them were subjects in group 3 and one among them was subject in group 2. No fatal $A E$ reported in all groups and no subject needed an inpatient treatment due to the $A E$. After a further investigation, only one case (dizziness) of $\mathrm{AE}$ that related to the administration of $\mathrm{CB}$ extract and 5 cases (abdominal pain) related to the administration of NSAID. There were no statistically different from the prevalence of $A E$ between groups at the visit II (p: 0.119) and the visit III (p: 0.767). Table 5 shows the detail of the $A E$ in each group.

Table 6: Number and type of adverse events

\begin{tabular}{|c|l|c|l|c|}
\hline Groups & \multicolumn{1}{|c|}{ Visit II } & $\mathrm{p}$ & \multicolumn{1}{c|}{ Visit III } & $\mathrm{p}$ \\
\hline Group 1 (n: 5) & 1 (mild lip swelling) & 0.119 & $\begin{array}{l}\text { 4 (flank pain, constipation, nausea and loss } \\
\text { of appetite, malaise, and dizziness) }\end{array}$ & 0.767 \\
\hline Group 2 (n: 4) & 2 (dizziness and urticaria) & & 2 (nausea and loss of appetite, dizziness) & \\
\hline Group 3 (n: 7) & 5 (abdominal pain) & & 2 (abdominal pain and muscle pain/spasm) & \\
\hline
\end{tabular}

\section{Discussion}

The present study aimed to identify the effectiveness of CB extract compared to the combination of CB extract and NSAID with NSAID alone. Each medication was taken two times per day for four weeks. The measurement was using WOMAC. The WOMAC was the most commonly used in OA patients. It used to measure the severity and frequency of symptoms. The higher scores indicate a higher severity (Grover and Samson, 2016).

The result of this study was indicated the administration of both CB extract and NSAID or its combination improve the symptom of OA (Table 3). Group 1 had the greater reduction of WOMAC score after four weeks of treatment, followed by group 2 and group 3 (Table 4). The administration of CB extract alone has a greater reduction in the severity and frequency of $\mathrm{OA}$ symptoms than the administration of NSAID alone. This study was similar to many previous studies. An administration of CL extract, BS extract, or its combination was beneficial in OA patients. About 201 subjects were investigated in a three-arm, parallelgroup, randomized, double-blinded, placebo-controlled trial to identify the effects of $333 \mathrm{mg}$ curcuminoids and a combination of $350 \mathrm{mg}$ curcuminoids and $150 \mathrm{mg}$ boswellic acid. The medication was taken orally three times a day for 12 weeks. The administration of a combination of curcumin and boswellic acid had a superior effect size (physical performance tests and the WOMAC joint pain index) than curcuminoid alone (Haroyan et al., 2018).

A study by Bolognesi et al. (2016) administered standard management of OA combined with oral supplementation in 26 subjects compared with a supplementation containing $\mathrm{N}$-acetyl-D- glucosamine, ginger, and BS extract. Significant improvements in the functional outcomes and pain-free walking distance were observed after 1, 3 and 6 months in OA patients supplemented with a combination of $\mathrm{N}$-acetyl-Dglucosamine, ginger, and BS extract (Bolognesi et al.,
2016). Treatment with BS extract showed a statistically significant $(p<0.001)$ decrease in WOMAC score after 120 days (Majeed et al., 2018)

In this current study, the CB extract group had the least consumption of rescue medication. Conversely, the NSAID group had the highest consumption of rescue medication (Table 5). A non-randomized, openlabeled, and non-comparative study by Reddy and Faruqui (2016) was using a combination of curcumin $500 \mathrm{mg}$ and piperine $5 \mathrm{mg}$ twice daily for 12 weeks. It showed that the assessment of the WOMAC score at the end of the 12th week showed a statistically significant change from baseline with a reduction in pain, stiffness, and physical function $(p<0.001)$ and showed a trend of decrease in need of rescue medication (Reddy and Faruqui, 2016).

The present study showed that the CB extract group had the least reported AE (Table 6). Nausea and loss of appetite were the most common type of $A E$ in subjects with $\mathrm{CB}$ extract medication. No fatal $A E$ was seen in $\mathrm{CB}$ extract group. The highest prevalence of $\mathrm{AE}$ seen in the NSAID group. NSAID group was also had more excluded subjects due to $A E$. This result is in concordance with previous studies. The number of AE of abdominal pain/discomfort was significantly higher in the ibuprofen group than that in the Curcuma domestica extracts group ( $p=0.046$ ) (Kuptniratsaikul et al., 2014). A review by Bee and Liew (2010) stated that turmeric and BS are generally well-tolerated. It may cause GIT side effects such as nausea and diarrhea. It was similar to the result of a study by Reddy and Faruqui (2016); three patients reported mild gastrointestinal $A E$. Supplementation with a combination of $\mathrm{N}$-acetyl-Dglucosamine, ginger, and BS extract are safe, welltolerated, and also showing the beneficial effect (Bolognesi et al., 2016).

There is still a very limited study which is investigating CB extract in OA patients in Indonesia. The limitation of this study was unblinded assessment of outcomes and a short length of treatment. This research 
did not receive any specific grant from funding agencies, in the public, commercial, or not-for-profit sectors.

\section{Conclusion}

$\mathrm{CL}$ extract in combination with $\mathrm{BS}$ extract effective for treatment in OA patients. It also has a great safety profile and well-tolerated compared to NSAID.

\section{Conflict of interest}

There are no conflicts of interest to disclose.

\section{References Références Referencias}

1. Akhtar N, Haqqi T M. Current nutraceuticals in the management of osteoarthritis: a review. Ther Adv Musculoskel Dis 2012; 4(3): 181-207.

2. Akuri M C, Barbalho SM, Val RM, Guiguer EL Reflections about Osteoarthritis and Curcuma longa. Pharmacogn Rev 2017; 11(21): 8-12.

3. Bee T A, Liew A. Dietary Supplements Used in Osteoarthritis. Proceedings of Singapore Healthcare 2010; 19(3): 237-247.

4. Bolognesi G, Belcaro G, Feragalli B, Cornelli U, Cotellese R, Hu S, Dugall M. Movardol ${ }^{\circledR}$ (N-acetylglucosamine, Boswellia serrata, ginger) supplementation in the management of knee osteoarthritis: preliminary results from a 6-month registry study. European Review for Medical and Pharmacological Sciences 2016; 20: 5198-5204.

5. Cedraschi C, Delezay S, Marty M, Berenbaum F, Bouhassira D, Henrotin $Y$, Laroche F, Perrot S. "Let's Talk about OA Pain": A Qualitative Analysis of the Perceptions of People Suffering from OA. Towards the Development of a Specific Pain OARelated Questionnaire, the Osteoarthritis Symptom Inventory Scale (OASIS). PLoS One 2013; 8(11): e79988.

6. Grover A K, Samson S E. Benefits of antioxidant supplements for knee osteoarthritis: rationale and reality. Nutrition Journal 2016; 15: 1.

7. Haroyan A, Mukuchyan V, Mkrtchyan N, Minasyan N, Gasparyan S, Sargsyan A, Narimanyan M, Hovhannisyan A. Efficacy and safety of curcumin and its combination with boswellic acid in osteoarthritis: a comparative, randomized, doubleblind, placebo-controlled study. BMC Complementary and Alternative Medicine 2018; 18: 7 .

8. Henrotin Y, Clutterbuck A L, Allaway D, Lodwig E M, Harris $P$, Mathy-Hartert $M$, Shakibaei M, Mobasheri A. Biological actions of curcumin on articular chondrocytes. Osteoarthritis Cartilage 2010; 18(2): 141-9.

9. Henrotin Y, Priem F, Mobasheri A. Curcumin: a new paradigm and therapeutic opportunity for the treatment of osteoarthritis: curcumin for osteoarthritis management. Springer Plus 2013; 2: 56.
10. Indonesian Rheumatology Association. "Diagnosis dan Penatalaksanaan Osteoartritis". Jakarta: Indonesian Rheumatology Association. 2014; pp 18-22.

11. Kuptniratsaikul V, Dajpratham $P$, Taechaarpornkul W, Buntragulpoontawee M, Lukkanapichonchut $P$, Chootip C, Saengsuwan J, Tantayakom K, Laongpech S Efficacy and safety of Curcuma domestica extracts compared with ibuprofen in patients with knee osteoarthritis: a multicenter study. Clinical Interventions in Aging 2014: 9 451-458.

12. Lespasio M J, Piuzzi N S, Husni M E, Muschler G F, Guarino A J, Mont M A. Knee Osteoarthritis: A Primer Perm J 2017; 21: 16-183.

13. Litwic A, Edwards M, Dennison E, Cooper C. Epidemiology and Burden of Osteoarthritis. Br Med Bull 2013; 105: 185-199.

14. Lluch E,Torres R, Nijs J, Oosterwijck J V. Evidence for central sensitization in patients with osteoarthritis pain: A systematic literature review. Eur J Pain 2014; 18: 1367-1375.

15. Loeser R F, Goldring S R, Scanzello C R, Goldring MB. Osteoarthritis: A Disease of the Joint as an Organ. Arthritis Rheum 2012; 64(6): 1697-1707.

16. Majeed $M$, Majeed $S$, Narayanan NK, Nagabhushanam K. A pilot, randomized, double-blind, placebo-controlled trial to assess the safety and efficacy of a novel Boswellia serrata extract in the management of osteoarthritis of the knee. Phytotherapy Research 2019; 1-12.

17. Mobasheri A, Mark B. An update on the pathophysiology of osteoarthritis. Annals of Physical and Rehabilitation Medicine 2016; 59(5-6): 333-339.

18. Neogi T. The Epidemiology and Impact of Pain in Osteoarthritis. Osteoarthritis Cartilage. 2013 Sep; 21(9): 1145-1153.

19. Reddy K R, Faruqui A A. Efficacy and tolerability of fixed dose combination of curcumin and piperine in Indian osteoarthritic patients. International Journal of Orthopaedics Sciences 2016; 2(4):445-449.

20. Siddiqui M Z. Boswellia Serrata, A Potential Antiinflammatory Agent: An Overview. Indian J Pharm Sci. 2011 May-Jun; 73(3): 255-261.

21. Sofat N, Kuttapitiya A. Future directions for the management of pain in osteoarthritis. Int $\mathrm{J}$ Clin Rheumtol 2014; 9(2): 197-276.

22. Sostres C, Gargallo C J, Lanas A. Nonsteroidal antiinflammatory drugs and upper and lower gastrointestinal mucosal damage. Arthritis Res Ther 2013; 15(Suppl 3): S3.

23. Umar S, Umar K, Sarwar A H, Khan A, Ahmad N, Ahmad S, Katiyar C K, Husain S A, Khan H A. Boswellia serrata extract attenuates inflammatory mediators and oxidative stress in collagen induced arthritis. Phytomedicine 2014; 21(6): 847-56. 